\title{
Water uptake strategies by typical broadleaf and coniferous trees in the Loess Plateau mountain area of northern China
}

\author{
Weiwen Zhao ${ }^{1}$, Youzhi Han ${ }^{1}$, Wenjun Liang ${ }^{1}$, and Xi Wei ${ }^{1}$ \\ ${ }^{1}$ Shanxi Agricultural University
}

December 22, 2020

\begin{abstract}
There are few precipitation events in the Loess Platea area, which may significantly influence water uptake strategies for plant communities, while water source for trees, growing in the Loess Plateau mountain area, are poorly comprehend. We investigated the impacts of precipitation (before and after) on water uptake strategies for typical broadleaf and coniferous trees using hydrogen and oxygen stable isotope techniques in the Loess Plateau mountain area of northern China. Our results indicated that water sources of the two plant species varied before and after rainfall. Robinia pseudoacacia largely absorbed water from $30-40 \mathrm{~cm}(57.8 \%)$ soil layers before precipitation and switched its main water source to $20-30 \mathrm{~cm}(58.5 \%)$ soil layer after precipitation. Contrary to R.pseudoacacia, Pinus tabuliformis mainly absorbed water from $20-30 \mathrm{~cm}(24.9 \%)$ and $10-20 \mathrm{~cm}$ $(21.6 \%)$ soil layers before precipitation and changed its dominant water sources to $0-10 \mathrm{~cm}(39.8 \%)$ and $10-20 \mathrm{~cm}(44 \%)$ soil layer after precipitation. Moreover, the herbaceous of broadleaf plant has the higher complex of the community. On the whole, R.pseudoacacia and P.tabuliformis showed the diverse characteristics of water utilization, which suggests that these two species are suitable for a mixed forest vegetation and our findings provide valuable information for planning long-term ecological afforestation management around the Loess Plateau mountain area of northern China.
\end{abstract}

\section{Hosted file}

Water uptake strategies by typical broadleaf and coniferous trees in the Loess Plateau mountain area of available at https://authorea.com/users/384377/articles/500007-water-uptake-strategies-bytypical-broadleaf-and-coniferous-trees-in-the-loess-plateau-mountain-area-of-northernchina

\section{Hosted file}

Table.pdf available at https://authorea.com/users/384377/articles/500007-water-uptakestrategies-by-typical-broadleaf-and-coniferous-trees-in-the-loess-plateau-mountain-areaof-northern-china 

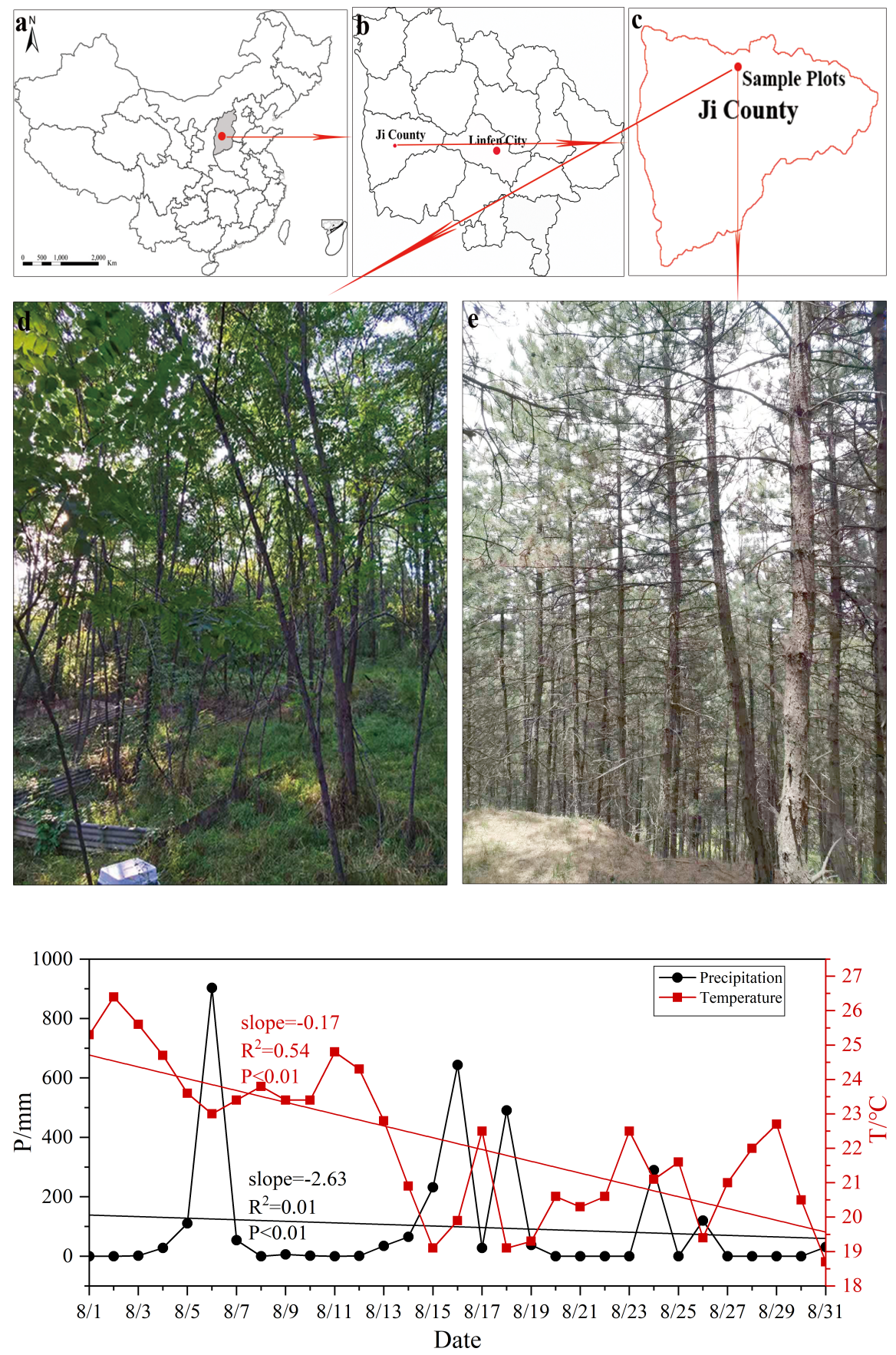

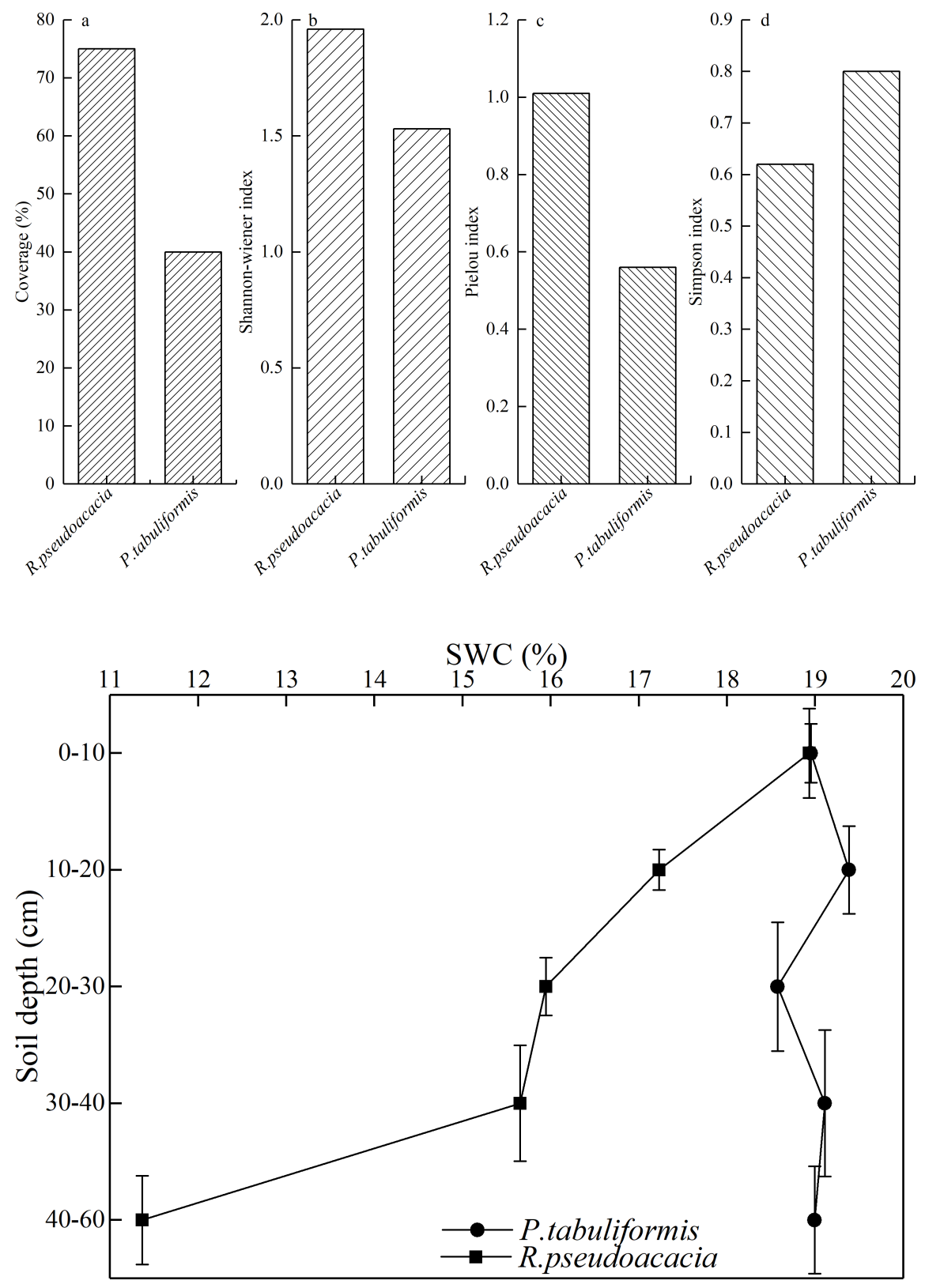

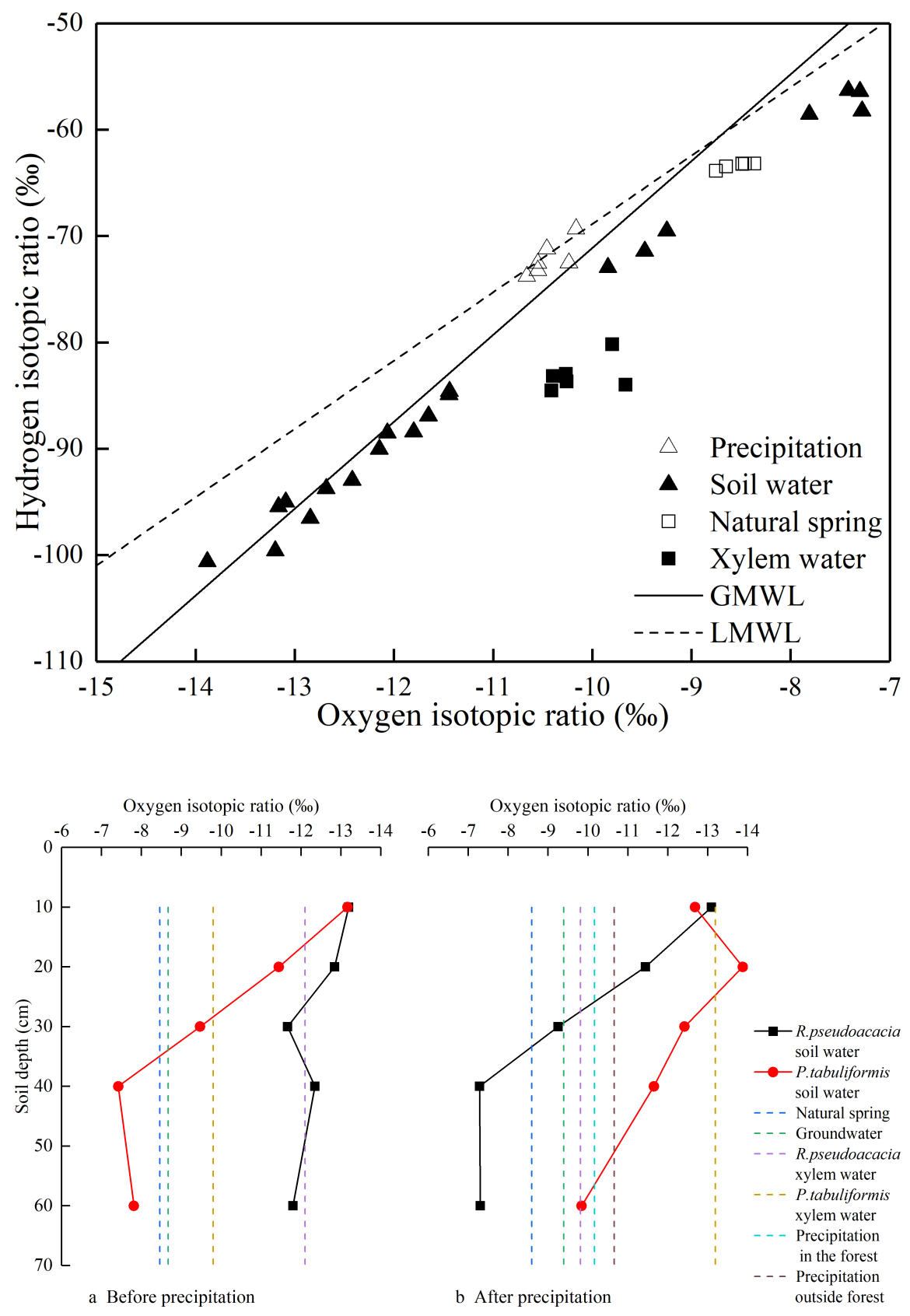

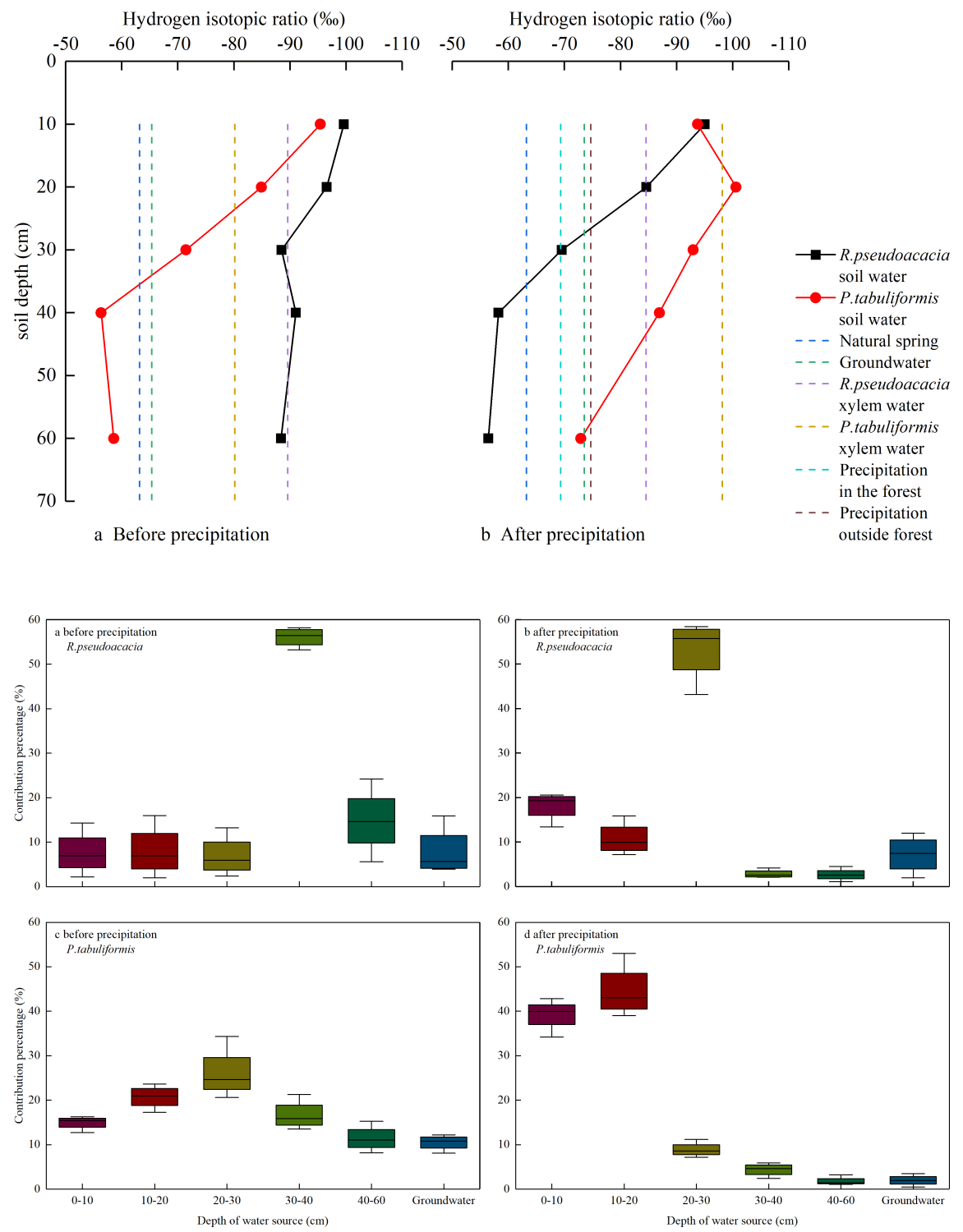